\title{
GPP and maximum light use efficiency estimates using different approaches over a rotating biodiesel crop
}

\author{
M.L. Sánchez*, N. Pardo, I.A. Pérez, M.A. García \\ Department of Applied Physics, University of Valladolid, Spain
}

\section{A R T I C L E I N F O}

\section{Article history:}

Received 11 November 2014

Received in revised form 1 September 2015

Accepted 20 September 2015

\section{Keywords:}

Biofuel crops

Rapeseed rotation crops

GPP

LUE models

MODIS GPP calibration

\begin{abstract}
A B S T R A C T
This paper presents: (a) results of gross primary production (GPP) 8-d estimated values using a light use efficiency model (LUE) in a non-irrigated rotating rapeseed crop in the upper Spanish plateau, and (b) inter-comparison results of observed GPP with those concurrently retrieved by MODIS. The rotation scheme over the four-year study comprised rapeseed, wheat, peas and rye. Rapeseed, peas and, in part, rye grew under well-watered conditions whereas wheat was dominated by drought.

Input data for the LUE model were the fraction of PAR absorbed (FPAR) 8-d products supplied by MODIS

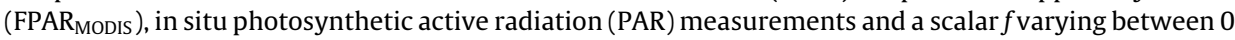
and 1 , to take into account the reduction of the maximum PAR conversion efficiency $\left(\varepsilon_{0 \text { LUE }}\right)$ under limiting environmental conditions. In this study, $f$ values were assumed to be dependent on air temperature $(T)$ and the evaporative fraction which was considered a proxy of water availability. $\varepsilon_{0 \text { LUE }}$, a key parameter in LUE models, which varied according to land use, was derived through the results of a linear regression fit between observed GPP and concurrent $\mathrm{G}_{\text {APAR }}$ estimates defined as the product of PAR, FPAR MODIs $_{\text {and }}$ $f$. Overall, the LUE model provided satisfactory results, $R^{2}=86.3 \%$, significantly improving GPP MODIS estimates $\left(\mathrm{GPP}_{\text {MODIS }}\right), R^{2}=71.8 \%$. GPP $\mathrm{MODIS}_{\text {Is }}$ uncertainties have primarily been attributed to differences in the $\mathrm{f}$ stress factor involved in its formulation $\left(f_{\text {MODIS }}\right)$ depending on vapour pressure deficit and $T$ which did not fully describe the environmental stress conditions at the measuring site.

Overall, $\varepsilon_{0 \text { LUE }}$ yielded $3.33 \pm 0.10 \mathrm{gCMJ}^{-1}$ although this varied depending on crop architecture, phenology and prevailing meteorological conditions. Crop-to-crop $\varepsilon_{0 \text { LUE }}$ ranged from $2.74 \pm 0.17$ to $3.95 \pm 0.19 \mathrm{gC} \mathrm{MJ}^{-1}$ for peas and rye, respectively, yielding intermediate values for rapeseed and wheat, $2.92 \pm 0.18$ and $2.86 \pm 0.23 \mathrm{gC} \mathrm{MJ}^{-1}$, respectively. $\varepsilon_{0 \mathrm{MODIS}}$, derived from the linear fit of GPP versus GPPMoDIs estimates, yielded $2.13 \pm 0.10 \mathrm{gCMJ}^{-1}$ and crop-to-crop ranged from $1.28 \pm 0.17$ to $2.41 \pm 0.12 \mathrm{~g} \mathrm{C} \mathrm{MJ}^{-1}$ for wheat and rapeseed, respectively. The best linear fits corresponded to crops growing under well-watered conditions, rapeseed and peas, and the worst fits were for wheat, affected by drought. GPP annuals were $1680,710,730$ and $1410 \mathrm{~g} \mathrm{C} \mathrm{m}^{-2}$ for rapeseed, wheat, peas and rye, respectively.
\end{abstract}

(c) 2015 Elsevier B.V. All rights reserved.

\section{Introduction}

Atmospheric $\mathrm{CO}_{2}$ concentrations, the major greenhouse contributor, increased from the pre-industrial value, $278 \mathrm{ppm}$, to $398.6 \mathrm{ppm}$ in 2014, the longest temporal series recorded in Mauna Loa (http://www.cmdl.noaa.gov) showing a steadily increasing trend. In this context, predicting gross primary production (GPP), the total amount of $\mathrm{CO}_{2}$ assimilated by plants, and net ecosystem exchange (NEE), the total amount of $\mathrm{CO}_{2}$ exchanged between the

\footnotetext{
* Corresponding author.

E-mail address: marisa@fa1.uva.es (M.L. Sánchez).
}

ecosystem and the atmosphere, is of crucial importance to evaluate the role of an ecosystem in the global carbon cycle.

Crops are of increasing concern in terrestrial ecosystems. The enormous potential of crops in greenhouse mitigation has recently been emphasized (Smith, 2004; Smith et al., 2008). Although crops are estimated to be the largest biospheric source of carbon lost to the atmosphere, current estimates remain uncertain and their behaviour as both a $\mathrm{CO}_{2}$ source (Schulze et al., 2009) or sink (Gilmanov et al., 2013; Jaksic et al., 2006; West et al., 2010) has been reported. Different management practices, such as tillage type, rotation schemes, irrigation and cropland expansion might be some of the reasons why crops are sources or sinks in different regions around the world (Tao et al., 2011). Climatic conditions 
are another driver involved in observed inter-annual variations (Pei et al., 2013).

GPP is indirectly derived by eddy covariance (EC) flux towers as the difference between NEE, and total ecosystem respiration (TER) during daylight. NEE is measured directly and TER may be parameterized using NEE nocturnal data on soil and/or air temperature. The increasing number of covariance flux towers in different biomes around the world has provided insights into significant NEE and consequently GPP geographical variability (Baldocchi et al., 2001; Baldocchi, 2008; Lafont et al., 2002; Reichstein et al., 2007; Running et al., 1999). Among existing predictive methods, light use efficiency models (LUE) are considered a robust tool since they describe GPP spatial and temporal variation. These models are based on the original concept of Monteith (Monteith, 1977) who suggested that GPP or net primary productivity (NPP) of wellwatered crops was linearly related to the amount of photosynthetic radiation absorbed by vegetation (APAR), the product of PAR and the fraction of PAR absorbed (FPAR). A PAR conversion efficiency factor, $\varepsilon$, translates APAR into GPP or NPP carbon units. FPAR can be measured directly or retrieved by remote sensing. The increasing number of orbiting satellites able to supply land vegetation products offers a powerful tool to estimate GPP at a global scale. Among these satellites, EOS MODIS (Moderate Resolution Imaging Spectroradiometer) from NOAA directly computes FPAR (FPAR MODIS $_{\text {) with }}$ a typical spatial resolution of $1 \mathrm{~km} \times 1 \mathrm{~km}$, thus affording an excellent opportunity to derive GPP and calibrate the results obtained in a specific geographical biome using ground measurements. The MODIS satellite also retrieves GPP 8-d composites thereby providing an additional advantage to inter-compare and validate these results with those derived from ground measurements (Fensholt et al., 2006; Gebremichael and Barros, 2006; Turner et al., 2003, 2005).

$\varepsilon$ depends on vegetation type and suboptimal climate conditions, such as water stress. In order to quantify $\varepsilon$, one common approach involves considering optimal light use efficiency $\left(\varepsilon_{0}\right)$ and including a suitable scalar $f$ with values ranging from 0 to 1 to take account of constraints in climate conditions:

$\varepsilon=\varepsilon_{0} \mathrm{f}$

$\varepsilon_{0}$ values, a key point in LUE models, differ enormously depending on their formulation. For instance, MODIS default values for 11 global biome classes vary from 0.604 to $1.259 \mathrm{~g} \mathrm{CMJ}^{-1}$ (Running et al., 2000), whereas the C-fix model (Veroustraete et al., 2002) considers a universal value of $1.1 \mathrm{gC} \mathrm{MJ}^{-1}$. Formulating LUE models also depends on how environmental stress constraints, namely $f$, are determined (Fensholt et al., 2006). Thus, the MODIS algorithm considers a multiplicative combination of two factors depending on the vapour pressure deficit $(D)$ and $T$, each ranging from 0 to 1 (Leuning et al., 2005). The $D$ scalar consideration is based on the fact that high $D$, typically above $20 \mathrm{hPa}$, have usually been linked with inducing stomata closure in non-irrigated plants. However, it has also been argued that the constraint imposed by $D$ does not always adequately describe water availability of plants, and several authors (Yuan et al., 2007) have proposed substituting the $D$ factor by the evaporative fraction (EF) defined as:

$\mathrm{EF}=\frac{\mathrm{LE}}{\mathrm{LE}+\mathrm{H}}$

where $(\mathrm{LE})$ and $(\mathrm{H})$ represent the latent and sensible heat fluxes. Other models include a third multiplicative factor, e.g., a soil moisture index (Prince and Goward, 1995) or a leaf phenology index (Li et al., 2007; Wang et al., 2010; Xiao et al., 2005).

The general aim of this paper is to present the most relevant results of GPP seasonal evolution over four years in a non-irrigated rotating biodiesel rapeseed crop in the upper Spanish plateau. The reasons for selecting this crop type are: (1) the large increase in cultivated areas in recent years due to the environmental benefits attributed to biodiesel fuels. (2) Biodiesel from rapeseed predominates in Europe, EU25 (Reijnders and Huijbregts, 2008). In Spain, rapeseed production and the planting surface approximately doubled from 2007 to 2011 (MAGRAMA, 2013). (3) The rapeseed rotation cycle, which typically extends over four or five years, provides a good opportunity to describe the behaviour of the different crops seeded at the same plot. The rotation cycle presented in this study consists of the non-irrigated annual rotation of rapeseed, wheat, peas and rye. A further contribution the paper makes is that it includes rye, a crop rarely studied.

The specific objectives of this paper are:

(1) To present and compare crop-to-crop seasonal evolution of observed GPP 8-d composites, GPP.

(2) To derive both an overall and a crop-to-crop LUE model. Particular attention is devoted to obtaining overall and crop-to-crop $\varepsilon_{0 \text { LUE }}$ values.

(3) To calibrate and assess the accuracy of the FPAR MODIs $_{\text {products }}$ using LAI ground-based measurements (LAI) performed during the growing season.

(4) To calibrate the GPP 8-d MODIS products overall and crop-tocrop.

\section{Materials and methods}

\subsection{Site description}

The experimental site is on the Monte de Rocío agricultural farm, which covers an area of $400 \mathrm{ha}$, and is located in the centre of the upper Spanish plateau ( $41^{\circ} 46^{\prime} 44.4^{\prime \prime} \mathrm{N}, 4^{\circ} 52^{\prime} 19.19^{\prime \prime} \mathrm{W}, 849 \mathrm{~m}$ a.m.s.l). The region is semi-arid with a Mediterranean-Continental climate characterized by low temperatures in winter months and warm and dry summers. The overall annual mean rainfall recorded at Villanubla Airport (close to the farm) is $450 \mathrm{~mm}$. The land use of the farm is a mosaic of rotating cereal crops, with wheat and barley predominating. The selected plot covers 36 ha and has its own electrical facilities in the centre, a feature which, combined with the very flat terrain of the area, offered extremely suitable conditions for micrometeorological measurements and hence, for providing robust NEE and GPP results. Agricultural practices at the selected plot applied during the period of measurements, 2008-2011, consisted of annual rotation of non-irrigated rapeseed, wheat, peas and rye crops, respectively. Reduced tillage practices were used which, as already reported (Sánchez et al., 2002), contribute to reducing $\mathrm{CO}_{2}$ soil efflux. Soil composition is sandy loam with an organic content between 60 and $65 \%$ sand, $20 \%$ clay, about $15 \%$ silt, and about $3 \%$ organic matter.

\subsection{Eddy covariance and meteorological data}

$\mathrm{CO}_{2}$ and water vapour fluxes were measured using a typical EC system consisting of a Licor 7500 infrared analyzer and a METEK USA- 1 sonic. The system operated at $10 \mathrm{~Hz}$ and was installed on a mast $3.5 \mathrm{~m}$ above the soil. Raw data were dually stored on a data logger and on a PC. These data were transferred daily by remote control to the Faculty of Sciences at the University of Valladolid and processed as 30-min averages. Raw data processing was performed by means of the TK2 software developed by the University of Bayreuth (Mauder and Foken, 2004). The processing steps included despiking, coordinate rotation, time lag correction, frequency response correction and Webb, Pearman and Leuning correction (Paredes, 2013). A second mast measuring $2.5 \mathrm{~m}$ was installed and equipped with slow response probes, a quantum sensor to measure PAR (LI190Sz, Li-Cor Inc., Lincoln, NE, USA), net solar radiation (model 
8110, Ph. Schenk), relative humidity and T (model STH-5031), wind speed and wind direction (wind sentry, model 03002, Young, Campbell Scientific, Inc.). Two soil heat flux plates (HFP01, HukseFlux, Delft, The Netherlands) and one soil moisture (SM) probe (model 6545, type ML2x, ThetaProbe) completed the instrumentation. All these data were continuously recorded on another data logger (Model Meteodata, Geónica), transferred daily by remote control to the Faculty of Sciences and finally processed as 30-min mean values.

NEE measurements commenced at the beginning of March 2008. The slow response meteorological probes were fully operational at the beginning of April in the same year. NEE 30-min diurnal gaps were filled using the Michaelis Menten equations fitted using PAR as input data on a monthly or fortnightly basis, the latter being used during the growing season (GS), from March to June. Nocturnal NEE gaps were filled using the results of the respiration fit equation (see below, Eq. (7)). The large gap, from November 2007 to February 2008, was filled using the results of a linear regression between GPP and concurrent LAI MODIS 8-d composites (see Section 2.4). Most meteorological data gaps from October 2007 to March 2008 were filled using the records from another station located some $10 \mathrm{~km}$ from the measuring site, which can be considered representative enough at the plot site due to the flat terrain and homogeneity in the meteorological conditions prevailing in the study area. The exception to this rule was SM and soil flux data, which were not available at the second station. The SM gaps in March 2008 were filled using the results of the linear regression between diurnal SM and diurnal EF obtained by averaging the 30-min concurrent records from April to October. From the relatively satisfactory correlation found between both variables, the determination coefficient $R^{2}$ was $64 \%$. Important inaccuracies in the TER calculation in March were neither expected nor detected after a detailed examination of the data set.

\subsection{Ancillary data (LAI)}

Except for peas, concurrent measurements of the canopy height and of the effective LAI evolution were performed during the GS. LAI measurements were carried out using a LAI-2000 (Plant canopy analyzer, Li-Cor) following Licor manual guidelines. Two series of five readings, with a sequence one above the canopy and four below the canopy, were performed in ten plants regularly distributed on a diagonal transect. Measurements were performed during daylight using a $270^{\circ}$ view cap. Readings were processed using the software provided by the manufacturer. Finally, the results obtained in individual plants were averaged each day of measurements. The number of measurements, limited to green canopy phenology, was 20,7 and 12, for rapeseed, wheat and rye. Whenever several measurements per week were performed, as in the case of rapeseed,

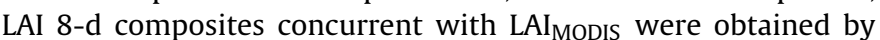
averaging available ground data.

\subsection{Remote sensing data}

MODIS Terra 8-d products, MOD15 for FPAR MODIS $_{\text {and }}$ LAI $_{\text {MODIS }}$ and MOD17 for GPP, were loaded from http://reverb.echo.nasa.gov/ during the whole period of study. From all the data extracted, in this paper we used those retrieved in the central pixel. To minimize the impact of noise, each final 8-d composite was obtained by averaging the corresponding data and the two neighbouring 8-d ones. Available MODIS data sets correspond to the V005 collection and have a spatial resolution of $1 \mathrm{~km} \times 1 \mathrm{~km}$. Available MODIS data sets correspond to the V005 collection and have a spatial resolution of $1 \mathrm{~km} \times 1 \mathrm{~km}$. Although the dimension of the pixel is higher than the plot size, minor inaccuracies in the MODIS products used in this paper could be expected due to: (1) its excellent geolocation accuracy, around $50 \mathrm{~m}$ (Hashimoto et al., 2012; Wolfe et al., 2002, 2012) and (2) the position of the EC system centred in the plot. This issue is addressed below using the LAI ground measurements performed (see Section 3.5).

\subsection{Model approach}

The methodology used in this paper is shown in the flow chart shown in Fig. 1. A detailed description is given below.

$\mathrm{GPP}_{\text {LUE }}$ was computed as follows:

$\mathrm{GPP}_{\mathrm{LUE}}=\varepsilon_{0} f_{\mathrm{LUE}} \mathrm{APAR}=\varepsilon_{0} \mathrm{G}_{\mathrm{APAR}}$

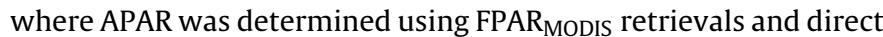
ground PAR measurements. In this paper, the stress f factor considered $\left(f_{\mathrm{LUE}}\right)$ is the product of two indexes, EF and a factor $T_{\mathrm{S}}$ depending on $T$ :

$f_{\mathrm{LUE}}=f\left(\mathrm{EF} T_{\mathrm{S}}\right)$

In this paper EF have been computed for $\mathrm{H}>0 \mathrm{~W} \mathrm{~m}^{-2}$ values. Low EF values, usually associated to low moisture are expected to be linked to water stress, and moderate or high values to sufficient water availability. EF can be derived using models based on satellite imagery (Elhag et al., 2011; Lu et al., 2013; Pardo et al., 2014; Venturini et al., 2008; Wang et al., 2006), which represents an additional advantage for upscaling purposes.

$T_{\mathrm{S}}$ index (Yuan et al., 2007) is given by:

$T_{\mathrm{S}}=\frac{\left(T-T_{\min }\right)\left(T-T_{\max }\right)}{\left[\left(T-T_{\min }\right)\left(T-T_{\max }\right)\right]-\left(T-T_{\mathrm{opt}}\right)^{2}}$

$T$ is the air temperature and $T_{\min }, T_{\max }, T_{\mathrm{opt}}$ the maximum, minimum and optimum air temperatures for photosynthesis activity. In this study, $T_{\min }$ and $T_{\max }$ considered were 0 and $36^{\circ} \mathrm{C}$. Negative $T_{\min }$ values were set to zero. The $T_{\max }$ value corresponds to the maximum 30-min record obtained during the study period $\sim 36^{\circ} \mathrm{C}\left(36.3^{\circ} \mathrm{C}\right)$. For $T_{\mathrm{opt}}$, we followed the same criteria as proposed by Albergel et al. (2010) based on the assumption that maximum efficiency is reached at the same temperature as GPP peaks. The optimum value was $18^{\circ} \mathrm{C}$, a result that is slightly lower than others reported in the literature, which range from $22^{\circ} \mathrm{C}$ (Patel et al., 2010) to $20.3^{\circ} \mathrm{C}$ (Yuan et al., 2007) for wheat and natural ecosystems, respectively.

GPP were obtained by subtracting direct NEE measurements obtained by the eddy covariance tower and the respiration term, TER:

$\mathrm{GPP}=-\mathrm{NEE}+\mathrm{TER}$

Since GPP only occurs during daytime, TER was computed using NEE nocturnal 30-min data by means of a modified Van't Hoff equation depending on $T$, which also takes SM into account:

$\mathrm{TER}=a \mathrm{SM} \exp (b T)$

Both unknowns, $a$ and $b$, were estimated using the Marquard algorithm for each type of crop during the period March-October. For the remaining months of the year, no distinction was made between crop type, and a similar simplified equation only dependent on $T$ was used. SM was excluded in this case because it did not lead to any improvement in the non-linear fit statistical results.

Nocturnal NEE 30-min observations were filtered using a friction velocity $\left(u^{*}\right)$ threshold of $0.15 \mathrm{~m} \mathrm{~s}^{-1}$. This threshold was determined using a combination of visual methods based on the analysis of nocturnal NEE statistical results at different $u^{*}$ intervals and the optimization of determination coefficients of non-linear fits (Papale et al., 2006; Reichstein et al., 2005). Diurnal TER 30-min were computed using nocturnal fitted equations by considering diurnal $T$ or both diurnal $T$ and SM 30-min data depending on the 


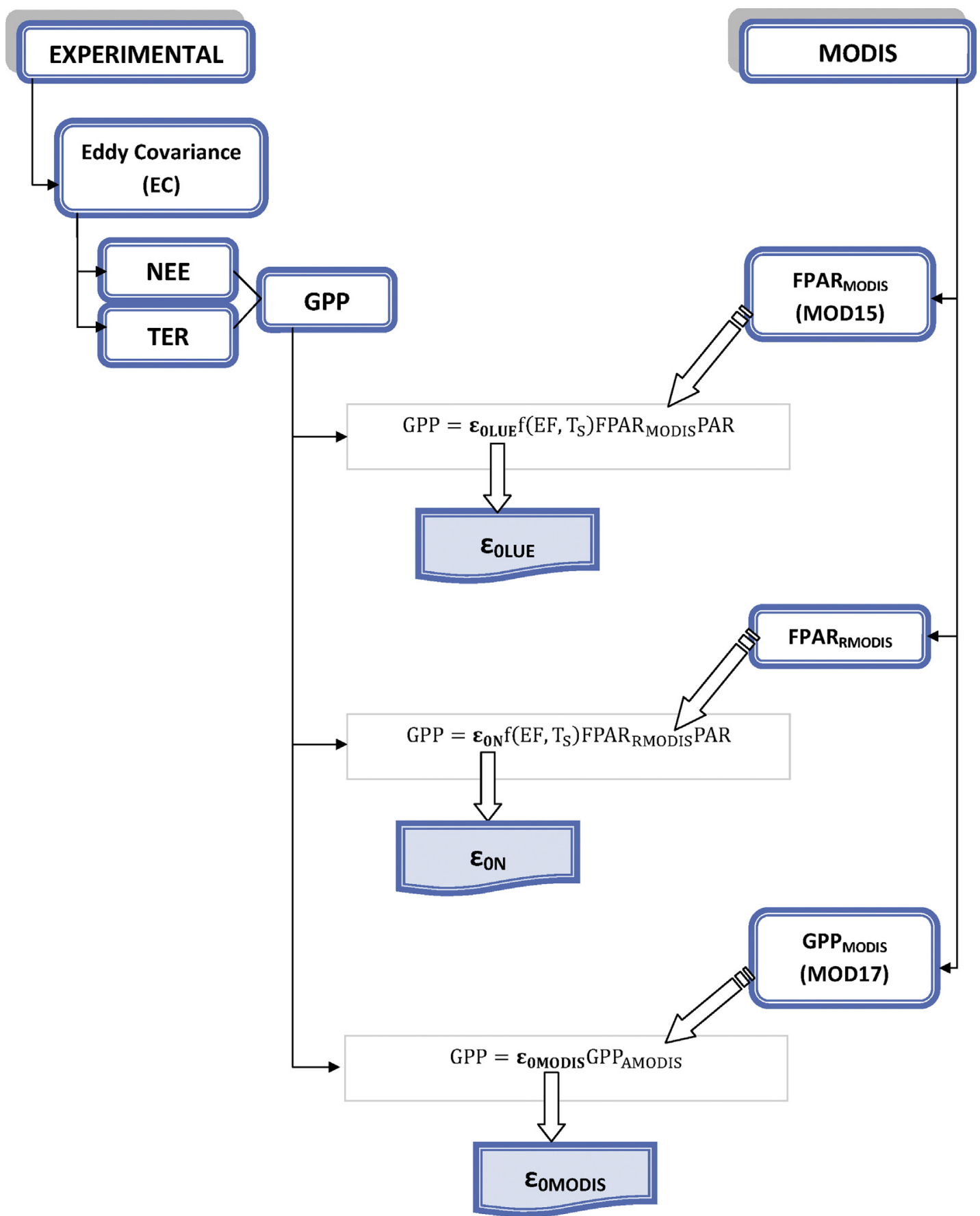

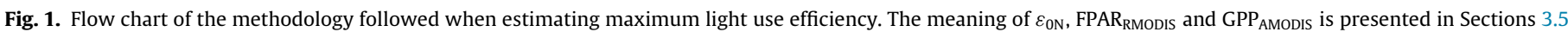
and 3.6.

period of the year. 8-d composites were determined by averaging 30-min data in each 8-d time period. For EF 8-d composites (EF) the same procedure was applied. Finally, $\varepsilon_{0 \mathrm{LUE}}$ was derived through the slope of the linear regression fit of the GPP values against concurrent $\mathrm{G}_{\mathrm{APAR}}$ estimates.

\subsection{Statistical analysis}

To evaluate the performances of the $\mathrm{GPP}_{\mathrm{LUE}}$, GPP $\mathrm{MODIS}_{\text {and }}$ antercomparison results in general, we used the following metrics in this study:
- The coefficient of determination $\left(R^{2}\right)$, which represents how much variation in the observations is explained by the model.

- The mean absolute error (MAE). It gives the average magnitude of the errors in a set of forecasts without considering their direction. It is computed by the following equation:

$\mathrm{MAE}=\frac{1}{n} \sum_{i=1}^{n}\left|y_{i}-o_{i}\right|$

where $y_{i}$ and $o_{i}$ are the simulated and observed values, respectively. 


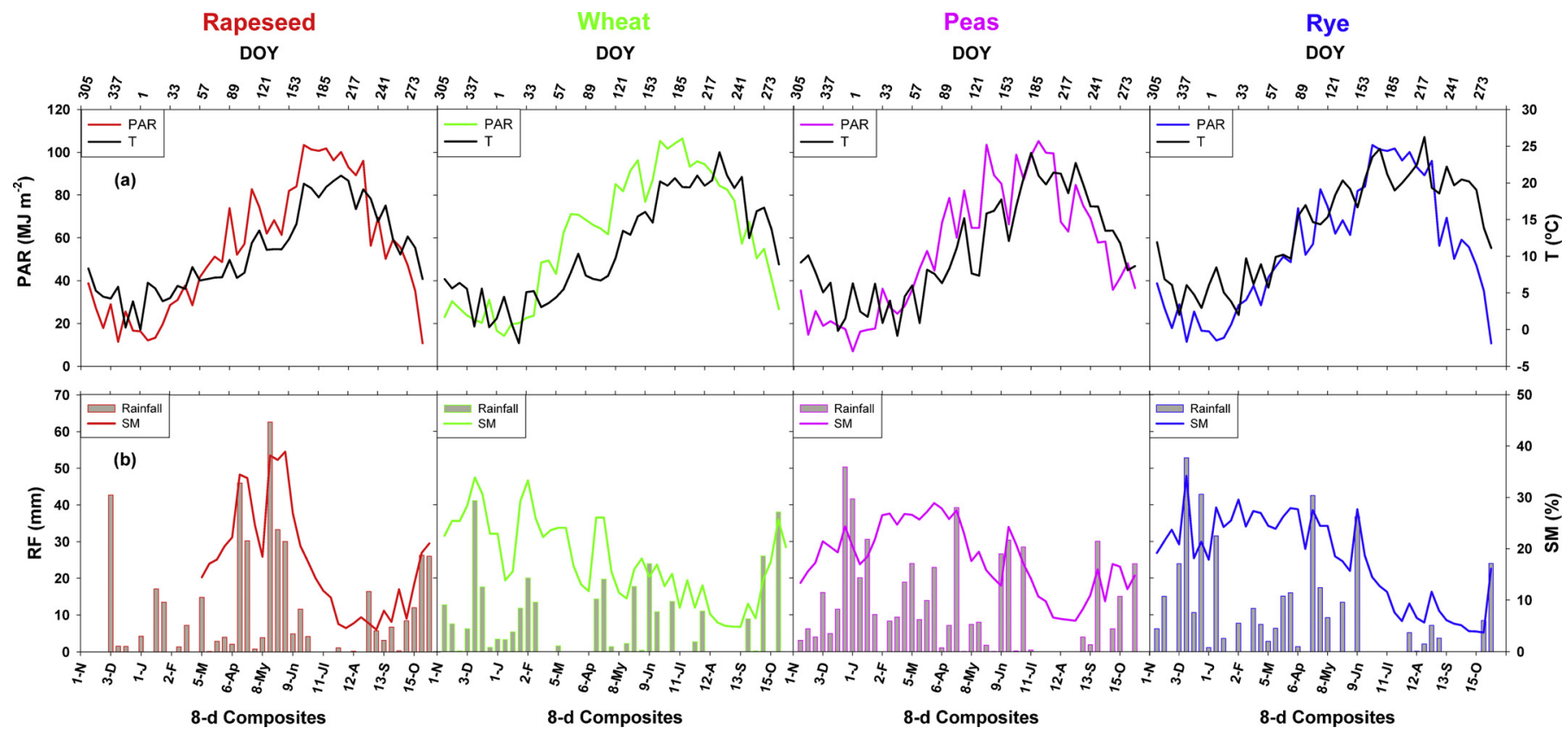

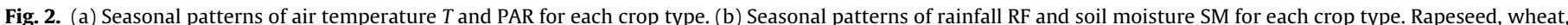

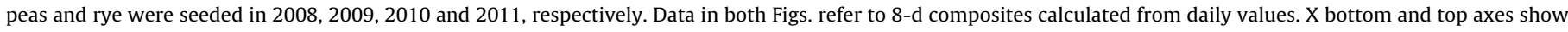
the date and DOY, respectively.

- The root-mean-square error (RMSE). This metric, one of the most frequently used, gives the standard deviation of the model simulated error using the following equation:

RMSE $=\sqrt{\frac{1}{n} \sum_{i=1}^{n}\left(y_{i}-o_{i}\right)^{2}}$

Since the errors are squared before bring averaged, RMSE gives a relatively high weight to large errors.

\section{Results}

Table 1 shows the period of seed of each crop type. As derived from this Table, seed time varied and ranged from mid September for rapeseed to late January in the case of peas. Harvest was always in mid July (from 12 th to 18 th).

The maximum canopy height $(h)$ of rapeseed, wheat and rye was $1.3,0.6$ and $1.6 \mathrm{~m}$ respectively, the values being reached at the end of May. Although no measurements were performed in the pea crop, according to the farmer's information the maximum height was approximately $0.45-0.5 \mathrm{~m}$, a typical value for this crop in the upper Spanish plateau.

\subsection{Meteorological driving variables}

Fig. 2a shows the patterns of 8-d composites for T and PAR, over the study period. Mean $T$ was $11.5^{\circ} \mathrm{C}$ and extreme values were $-1.8^{\circ} \mathrm{C}$ and $24.2^{\circ} \mathrm{C}$. Maximum and minimum values were reached

Table 1

Time of seed and harvest, maximum canopy height $h$ and maximum ground-based LAI for each type of crop.

\begin{tabular}{lllcl}
\hline Crop & Time of seed & Time of harvest & $h(\mathrm{~m})$ & LAI \\
\hline Rapeseed & $20 / 09 / 2007$ & $18 / 07 / 2008$ & 1.3 & 2.6 \\
Wheat & $06 / 11 / 2008$ & $14 / 07 / 2009$ & 0.6 & 2.2 \\
Peas & $25 / 01 / 2010$ & $12 / 07 / 2010$ & $\sim 0.45-0.5$ & - \\
Rye & $22 / 10 / 2010$ & $13 / 07 / 2011$ & 1.6 & 2.3 \\
\hline
\end{tabular}

in July-August and in December-January. PAR mean and extreme values were $56.3,7.0$ and $106.4 \mathrm{MJ} \mathrm{m}^{-2} .{ }^{1} 2008$ was the most temperate year, with extreme values of 0.0 and $21.0^{\circ} \mathrm{C}$, and also the cloudiest, especially in May. The remaining years displayed similar seasonal features. Fig. 2b depicts the rainfall 8-d (RF) and SM 8-d (SM) patterns. RF patterns show the typical seasonal variation in the studied area featured by two peaks, the first in spring, April-May, and the second in autumn-winter, from October to January, depending on the years. RF in summer, July-August and to some extent September, is normally very weak. From the comparison between RF year-to-year patterns, substantial variability is in evidence. 2008 was a "normal" year, with the yearly accumulated rainfall being $447 \mathrm{~mm}$, although it was also the rainiest in the GS (March-June, DOY 57-177), with an accumulated rainfall of $252 \mathrm{~mm}$. 2010 was the rainiest year, with an accumulated yearly rainfall of $517 \mathrm{~mm}$ which dropped dramatically to $336 \mathrm{~mm}$ in 2009. This latter year was dominated by drought. In the GS, accumulated rainfall dropped to $106 \mathrm{~mm}$ in contrast to 2010, $220 \mathrm{~mm}$. 2011 can be considered overall close to a "normal" year but it was dry in the GS, with the accumulated yearly and in the GS rainfall being $426 \mathrm{~mm}$ and $161 \mathrm{~mm}$. As expected, year-to-year SM patterns were consistent with those for RF; 2010 exhibited the highest SM records and 2009 the lowest, particularly in spring, with mean annual values being 25.4 and $17.6 \%$, respectively. Extreme SM values ranged from 3.7 to $40.8 \%$. The very low values recorded in mid summer, July-August, and even the first fortnight of September reveal the low soil water availability due to the increased temperature, lack of vegetation after harvest and weak rainfall at the measuring site. Another interesting feature is the similarity in SM and rainfall events. SM peaks tended to occur in phase with RF events. The SM lags occasionally found, e.g., mid September 2008 (DOY 265) and early June 2010 (DOY 153), might be attributed to heavy or moderate rainfall occurring over the last few days of the 8 -d composite. The lack of agreement of peaks sometimes found in

\footnotetext{
1 A conversion of 4.6 between MJ and mol PAR is used in this study (Yuan et al.,
} 2007). 


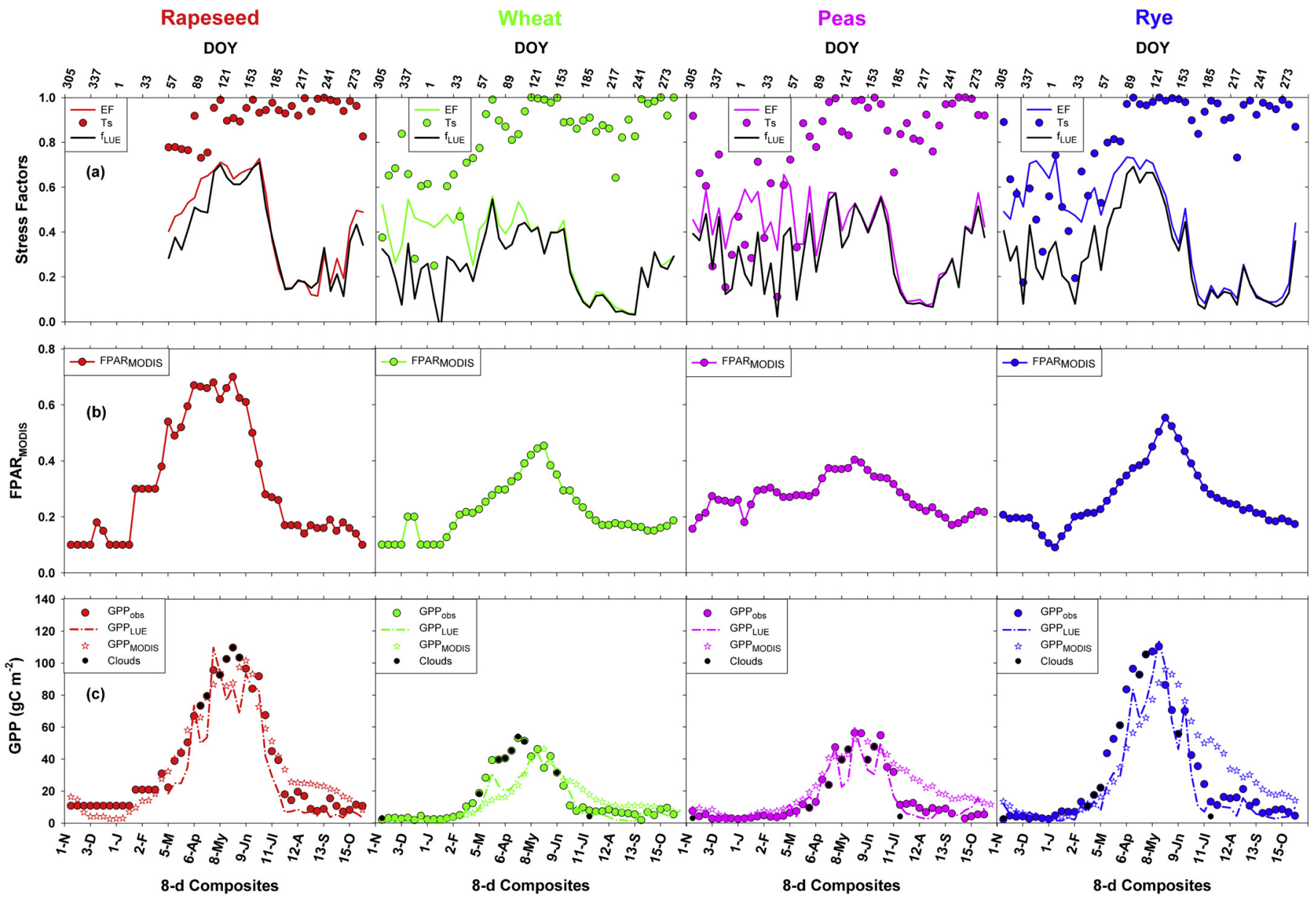

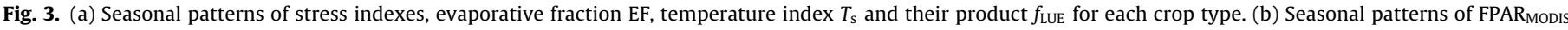

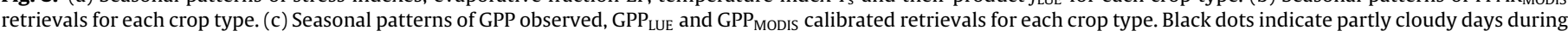

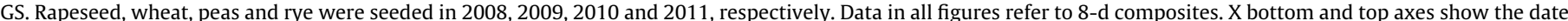
and DOY, respectively. The GPP MODIs results are presented below, see Section 3.6.

late spring or summer could be due to the local character of rainfall. One example is mid July, 2009 (DOY 193), in which rainfall was not measured at Villanubla station, yet when an increase in SM, indicative of rainfall occurrence, was recorded at the measuring site.

\subsection{Stress indexes}

Fig. 3a depicts the seasonal course of EF measured by EC, $T_{\mathrm{s}}$, and $f_{\text {LUE }}$ over the study period. The comparison between the EF year-toyear patterns reveals certain analogies and differences. Among the analogies, the systematic increase in EF during autumn and winter (October-January) is worthy of note, reaching maximum values of 0.6. This behaviour is consistent with the increase in SM resulting from increased rainfall. Abrupt visible peaks, as in the case of SM, tended to occur in phase with rainfall events or with an eight-day delay (see Fig. 2b). Another common feature was the EF decline during summer, from July to September, dropping by up to around 0.1 . These low values are a result of the dramatic decline in LE (values rarely exceeded $60 \mathrm{~W} \mathrm{~m}^{-2}$ ) and the increase in $H$ (values above $520 \mathrm{~W} \mathrm{~m}^{-2}$ ).

Despite the similarities between EF seasonal patterns in the GS, seasonal EF courses evidenced substantial variability. Rapeseed, the crop with the highest evapotranspiration, showed the greatest EF value, 0.73 , as well as a marked seasonal pattern. EF progressively rose from March to early May, reached a plateau until approximately mid June (DOY 169) and then declined sharply. Rye behaved in a similar manner, with the EF peak reaching 0.69 , although the decline was earlier, and occurred in mid May (DOY 129). Differences in the seasonal shape of both crops are in agreement with prevailing environmental conditions, especially rainfall, as well as their different architecture and phenology. Although both crops grew under well-watered conditions, May 2008 was the rainiest month, with a rainfall of $130 \mathrm{~mm}$, whereas May 2011 was significantly drier, with rainfall being $23 \mathrm{~mm}$. The higher and lower accumulated rainfall during the rapeseed and rye growing period, might have contributed to significantly delaying and bringing forward the senescence period, respectively. Rapeseed commenced the flowering period in early April, pod formation started in early June, and senescence was clearly visible in late June. During these phenological stages, LE remained relatively high (upper quartiles, 241 and $298 \mathrm{~W} \mathrm{~m}^{-2}$ in May and June as compared with those for $\mathrm{H}, 143$ and $172 \mathrm{~W} \mathrm{~m}^{-2}$ ), resulting in elevated EF values in May and most of June. Rye behaved similar to conventional grain crops at the measuring site. Heading took place in early May, and the onset of senescence was visible in early June, particularly in the lower and mid canopy. The LE upper quartiles were 236 and $224 \mathrm{~W} \mathrm{~m}^{-2}$ in April and May, exceeding those for $H, 100$ and $187 \mathrm{~W} \mathrm{~m}^{-2}$.

In contrast, wheat and especially peas did not show such an evident EF seasonal variation during growing. Peaks were significantly lower, 0.54 and 0.57, and were recorded in mid April 2009 (DOY 105) and mid-late April 2010 (DOYS 105, 113), respectively. 
In the case of wheat, EF likely remained lower than the expected values in well-watered conditions due to drought in 2009. Maximum LE values tended to be below $250 \mathrm{~W} \mathrm{~m}^{-2}$ (upper quartile, 155 and $142 \mathrm{~W} \mathrm{~m}^{-2}$ in April and May) and were generally lower compared to $H$, (upper quartile, $172,255 \mathrm{~W} \mathrm{~m}^{-2}$ the same months). The irregular EF shape of peas, another well-watered crop, might be attributed to the superimposed effects of rainfall peaks, e.g., DOY 49 and 81, the later emergence period and lower evapotranspiration due to its architecture and a lower canopy height. Maximum LE values in the GS generally remained below $250 \mathrm{~W} \mathrm{~m}^{-2}$ (upper quartiles 180 and $168 \mathrm{~W} \mathrm{~m}^{-2}$ in April and May), and were of a similar order of magnitude to $H$ (upper quartile 158 and $192 \mathrm{~W} \mathrm{~m}^{-2}$ the same months).

From late February to late June, $T_{\mathrm{s}}$ values ranged from 0.7 to 1 , most data being close to 1 , leading to a great similarity between EF and $f_{\text {LUE }}$ patterns. Similar results were obtained in summer and autumn. The lowest $T_{\mathrm{S}}$ values were reached in winter, dropping by up to $0.2-0.3$. These results suggest that the $T_{\mathrm{S}}$ stress index has no significant impact on GPP most of the time, except in winter, a period in which GPP reaches the minimum values (see below).

\subsection{FPAR MODIS retrievals}

The FPAR $_{\text {MODIS }}$ patterns depicted in Fig. $3 b$ followed the expected seasonal evolution consistent with growing. FPAR MODIS $_{\text {S }}$ progressively increased from late February, peaked in May and then began to decline, reaching minimum values in central summer and winter. Despite the similarities in the year-to-year patterns, some differences in magnitude and shape can be distinguished. Rapeseed

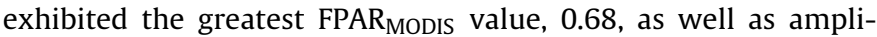
tude, with a plateau spreading over April-May and early June. As mentioned above, the plateau corresponded to flowering and the

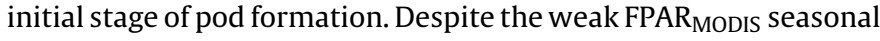
amplitude, peas behaved in a similar manner, with a plateau lasting approximately three months, from mid April to late June (DOY 97176). Peas exhibited the lowest FPAR $_{\text {MODIs }}$ peak, 0.40 , and values remained relatively high, close to 0.23 , in most of July. The shape of these seasonal courses contrasts with those corresponding to wheat and rye. In both cases, FPAR MODIS $_{\text {also showed a progres- }}$ sive increase followed by a decline although no significant plateau was observed. As in the two preceding crops, maximum values, 0.45 and 0.55 , were reached in mid May. The comparison between year-to-year patterns reveals that MODIS satisfactorily reflected the main features of the crops as well as the expected FPAR MODIS decline in 2009 that affected wheat due to the drought as compared with rapeseed and rye. The contrast between FPAR MODIS $_{\text {of rape- }}$ seed and peas is an evident example consistent with the different architecture of both crops.

\subsection{GPP, LUE model results}

The crop-to-crop GPP seasonal pattern is depicted in Fig. 3c. GPP rose from March to May and then declined sharply, reaching minimum values in central summer and winter. Rapeseed, pea and rye GPP peaks, 110,56 and $110 \mathrm{~g} \mathrm{C} \mathrm{m}^{-2} 8$-d respectively, occurred in mid May (DOY 129), late May (DOY 145) and early May (DOY 121) whereas in the case of wheat, the peak, $53 \mathrm{~g} \mathrm{C} \mathrm{m}^{-2} 8$-d, was earlier, in mid to late April (DOY 113). The different crops again showed certain differences in seasonal cycle amplitude. Rapeseed and rye presented the broadest seasonal cycle, spanning from March to mid-early July, 143 days (DOY 57-200) and 135 days (DOY 57-192), respectively, whereas wheat and peas exhibited shorter seasonal cycles, 123 and 104 days, from late February to late June (DOY 41184) and from early April to early July, (DOY 89-193), respectively. Annual accumulated GPP was $1680,710,730$ and $1410 \mathrm{~g} \mathrm{C} \mathrm{m}^{-2}$ for rapeseed, wheat, peas and rye.

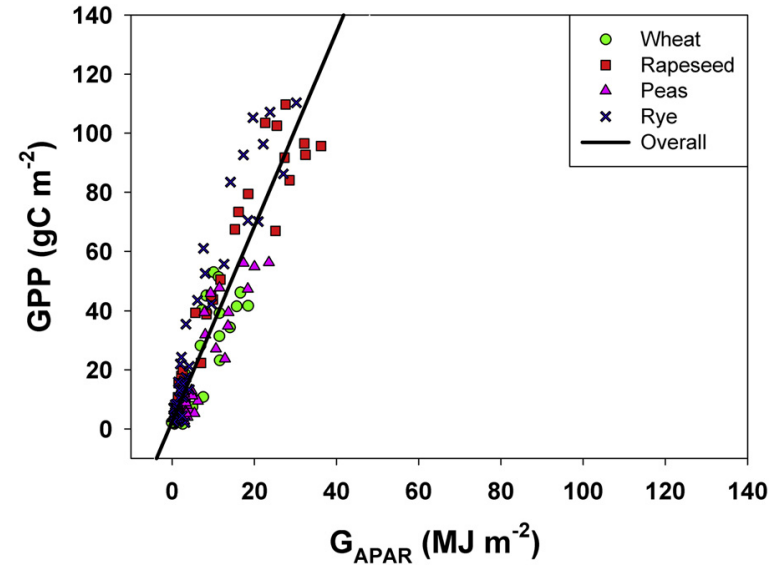

Fig. 4. Linear fit of observed GPP versus modelled $G_{A P A R}$ for each crop type. Red green, pink and blue symbols correspond to rapeseed, wheat, peas and rye, respectively, seeded in 2008, 2009, 2010 and 2011. The black line shows the overall linear fit for rapeseed, wheat, and rye. (For interpretation of the references to color in this figure legend, the reader is referred to the web version of the article.)

As pointed out earlier, $\varepsilon_{0 \text { LUE }}$ was derived through the slope of a linear regression fit between the GPP and $G_{A P A R}$ results as defined in Eq. (3). Fig. 4 shows the results of the linear fit. Coloured symbols, red, green, pink and blue, correspond to rapeseed, wheat, peas and rye, with the bold black line corresponding to the overall fit. Table 2 summarizes the parameter estimates overall and for each individual crop, the intercept (a), the slope $\left(\varepsilon_{0}\right), R^{2}$, MAE, and RMSE. Overall, $R^{2}$ yielded $86.1 \%$, the intercept was close to zero, $2.75 \mathrm{~g} \mathrm{C} \mathrm{m}^{-2} 8$-d, and the slope, $\varepsilon_{0 \text { LUE }}$, $3.33 \pm 0.10 \mathrm{~g} \mathrm{C} \mathrm{MJ}^{-1}$. Crop-to-crop results also proved satisfactory, with $R^{2}$ ranging from 90.8 to $77.8 \%$ for rapeseed and wheat, respectively. The $\varepsilon_{0 \text { LuE }}$ extreme values obtained were $3.95 \pm 0.19 \mathrm{~g} \mathrm{CMJ}^{-1}$ for rye, and $2.74 \pm 0.17 \mathrm{gC} \mathrm{MJ}^{-1}$ for peas, respectively. $\varepsilon_{0 \mathrm{LUE}}$ for rapeseed and wheat yielded intermediate values of $2.92 \pm 0.18$ and $2.86 \pm 0.23 \mathrm{~g} \mathrm{C} \mathrm{MJ}^{-1}$, respectively.

The comparison between the GPP and GPP in Fig. $3 c$ illustrates the general good agreement of the modelled results. However, from this figure certain discrepancies between both temporal series in GS are evident, especially in April. Most of these and, in particular, underestimation of the modelled results, occurred under partly cloudy 8-d days, shown as black dots in this figure. In this study, partly cloudy days were visually identified by

Table 2

Optimal light use efficiency, $\varepsilon_{0}\left(\mathrm{gC} \mathrm{MJ}^{-1}\right)$, intercept, a $\left(\mathrm{gC} \mathrm{m}^{-2}\right)$, determination coefficient, $R^{2}(\%)$, mean absolute error, $\operatorname{MAE}\left(\mathrm{g} \mathrm{C} \mathrm{m}^{-2}\right)$, and root mean square error, RMSE $\left(\mathrm{g} \mathrm{C} \mathrm{m}^{-2}\right)$, overall and for each crop type, rapeseed, wheat, peas and rye, seeded in 2008, 2009, 2010 and 2011. LUE and ON subscripts refer to the results of the LUE model using FPAR MODIS $_{\text {and FPAR }}$ RMODIS, respectively. MODIS subscript refers to GPP 8-d calibrated retrievals, see Section 3.6.

\begin{tabular}{lccccc}
\hline Results of Fits & Overall & Rapeseed & Wheat & Peas & Rye \\
\hline$\varepsilon_{\text {OLUE }}$ & 3.33 & 2.92 & 2.86 & 2.74 & 3.95 \\
$a_{\text {LUE }}$ & 2.75 & 10.07 & 2.30 & 0.58 & 5.05 \\
$R^{2}$ LUE & 86.1 & 90.8 & 77.8 & 85.4 & 90.3 \\
MAE $_{\text {LUE }}$ & 7.7 & 8.8 & 5.0 & 4.5 & 7.5 \\
RMSE $_{\text {LUE }}$ & 10.8 & 11.2 & 7.7 & 6.6 & 10.7 \\
$\varepsilon_{0 \mathrm{~N}}$ & 2.57 & 2.41 & 1.99 & 1.99 & 3.05 \\
$a_{0 \mathrm{~N}}$ & 3.30 & 10.24 & 3.43 & 1.45 & 5.75 \\
$R^{2}{ }_{\text {ON }}$ & 83.2 & 90.5 & 72.7 & 87.7 & 85.9 \\
MAE $_{\text {ON }}$ & 8.1 & 9.0 & 5.6 & 4.0 & 9.2 \\
RMSE $_{0 \mathrm{~N}}$ & 11.9 & 11.4 & 8.6 & 9.2 & 12.5 \\
$\varepsilon_{0 \text { MODIS }}$ & 2.13 & 2.41 & 1.28 & 1.75 & 2.30 \\
$a_{\text {MODIS }}$ & -3.21 & 0.06 & 1.70 & -5.66 & -2.24 \\
$R^{2}{ }_{\text {MODIS }}$ & 71.7 & 89.8 & 55.5 & 85.9 & 66.5 \\
MAE $_{\text {MODIS }}$ & 10.7 & 8.7 & 7.5 & 6.5 & 19.9 \\
RMSE $_{\text {MODIS }}$ & 14.8 & 10.6 & 10.9 & 5.1 & 7.5 \\
\hline
\end{tabular}




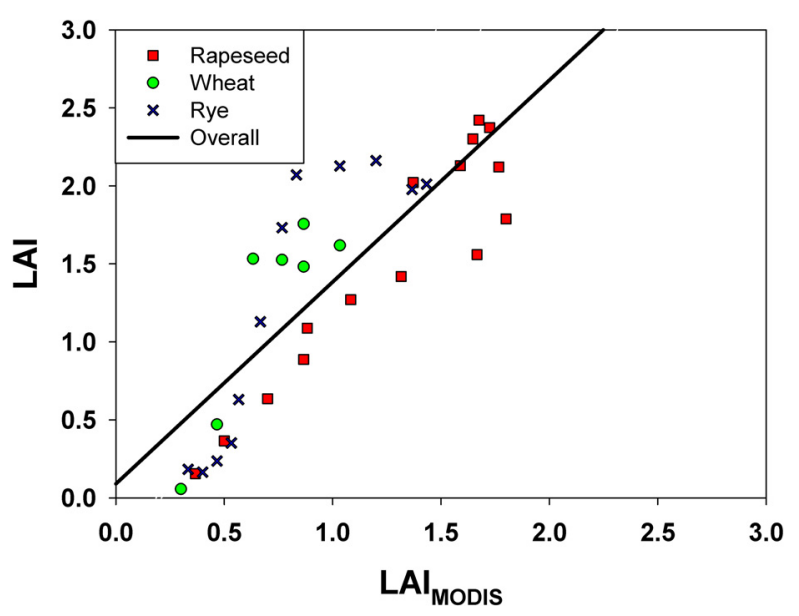

Fig. 5. Linear fit of ground based LAI versus $\mathrm{LAI}_{\mathrm{MODIS}} 8$-d composites. The black line shows the overall linear fit for rapeseed, wheat, and rye. Red, green, and blue symbols show the individual data for each crop type. (For interpretation of the references to color in this figure legend, the reader is referred to the web version of the article.)

observation in significant PAR anomalies compared to the maximum values recorded during GS at each corresponding month of the year. During these days, PAR declined leading to a decrease in $G_{\text {GPP }}$ as a result of its direct influence on LUE model formulation in contrast to GPP which remained significantly higher. The GPP $\mathrm{LUE}_{\mathrm{E}}$ underestimation obtained suggests that the light use efficiency, $\varepsilon$, on partly cloudy days tends to increase compared to that on clear days, a result which concurs with others reported (King et al., 2011; Sims et al., 2005).

\subsection{Calibration of FPAR $R_{M O D I S}$ using LAI ground measurements}

GPP seasonal evolution at our measuring site was regulated by $\mathrm{EF}$, the major stress factor, and FPAR. Both variables correlated well with GPP/PAR during the GS $\left(R^{2}=71.2 \%\right)$, EF and FPAR MODIS accounting for 49.9 and $61.1 \%$ of the variance of the linear fit, thus indicating their joint contribution to GPP seasonal evolution. Hence, bias in EF or FPAR might be considered as an important error source of GPP estimates. Based on the satisfactory closure of energy balance, 93\% (Pardo et al., 2015), bias in EF is not expected to lead to any significant error in GPP. Regarding FPAR, MODIS captured seasonal and inter-annual variations of each crop type reasonably well, retrievals proving consistent with their architecture and water stress. However, underestimation or overestimation of FPAR, the major driver of GPP at our measuring site, causes the opposite effects on $\varepsilon_{0}$. In an attempt to analyse possible FPAR MODIS $_{\text {inaccu- }}$ racies and their influence on $\varepsilon_{0}$, as pointed out earlier (see Section 2.4), we used the ground measurements performed at the plot as a support. The procedure followed is described below.

FPAR direct measurements are usually sparse. An alternative is to estimate FPAR on NDVI (Sims et al., 2005). Another commonly used approach is to derive FPAR from direct measurements of LAI using the Lambert-Beer equation:

$\mathrm{FPAR}=1-\exp (-K \mathrm{LAI})$

where $K$ is the light extinction coefficient.

As stated earlier, LAI measurements were regularly performed during the GS covering the main phenological stages of rapeseed and rye. In the case of peas, no measurements were conducted, and for wheat the number of measurements was primarily limited to May. These data enable us to perform an inter-comparison exercise between concurrent $\mathrm{LAI}$ and $\mathrm{LAI}_{\mathrm{MODIS}}$ products. The results of the linear regression of LAI versus the $\mathrm{LAI}_{\text {MODIS }}$ composites are depicted in Fig. 5. The black line shows the linear fit for the three crops,

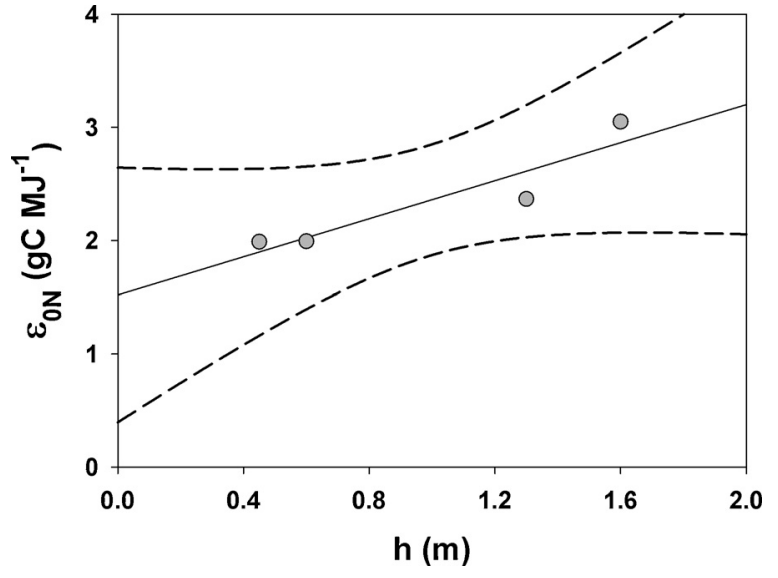

Fig. 6. Linear fit of optimal light use efficiency $\varepsilon_{0 \mathrm{~N}}$ versus canopy height $h$. $\varepsilon_{0 \mathrm{~N}}$ values correspond to those obtained with the LUE model using recomputed FPAR RMODIS input data derived from LAI ground data. Dotted lines are the confidence intervals at $95 \%$ significance level.

and red, green, and blue symbols identify the individual results for each crop type. A quick look at this Figure allows us to conclude the systematic underestimation of LAI $_{\text {MODIS }}$ versus LAI on overall as well as for each individual crop type. Since the intercept of the fit was close to zero, the slope, 1.334, directly accounts for MODIS underestimation. $R^{2}$ of the linear fit was moderately satisfactory, $67.6 \%$, the greater deviations being for rye. Based on this finding, the FPAR MODIS $_{\text {composites were re-computed using }}$ Eq. (10) as follows: (1) the $K$ parameter of FPAR $\mathrm{MODIS}_{\text {is }}$ was fitted

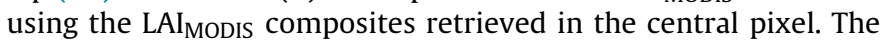
$K$ parameter estimates yielded $0.69 \pm 0.02\left(R^{2}=86.9 \%\right)$, a value in the range of other reported results (Atwell et al., 1999; O'Connell et al., 2004). This approach allows the original FPAR MODIS $_{\text {com- }}$ puted with a robust algorithm to be preserved, deriving the $K$ values by using the Lambert-Beer equation. (2) A new FPAR 8-d temporal series (FPAR RMODIS) was re-computed using the product of $K$ parameter estimates by the re-computed LAI MODIs retrievals (LAI MODIs retrievals multiplied by 1.334). Due to limited ground data, no distinction between crops was made. Hence, the new FPAR temporal series (FPAR RMODIS $_{\text {) }}$ should be considered as a calibration of the MODIS results at the central pixel based on ground LAI observations over the whole period studied. As expected, the

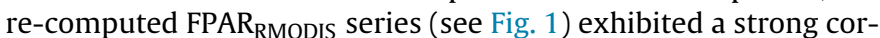
relation with the original temporal series, $R^{2}=88.2 \%$, although it obviously yielded higher values, which were higher by an average factor of 1.23 , leading to the subsequent decline in $\varepsilon_{0}$ values $\left(\varepsilon_{0 \mathrm{~N}}\right)$ obtained with the LUE model using FPAR $\mathrm{RMODIS}$ derived from LAI ground measurements, $2.57 \pm 0.09 \mathrm{~g} \mathrm{CMJ}^{-1}\left(R^{2}=83.2 \%\right)$. The results of the linear fits, overall and for each individual crop, namely, the intercept a, the slope $\varepsilon_{0 \mathrm{~N}}, R^{2}$, MAE and RMSE are shown in Table 2. Crop-to-crop re-computed FPAR RMODIS series yielded $\varepsilon_{0 \mathrm{~N}}$ values of $2.41 \pm 0.14 \mathrm{gCMJ}^{-1} \quad\left(R^{2}=90.5 \%\right)$, $1.99 \pm 0.18 \mathrm{~g} \mathrm{CMJ}^{-1} \quad\left(R^{2}=72.7 \%\right), 1.99 \pm 0.11 \mathrm{gCMJ}^{-1} \quad\left(R^{2}=87.7 \%\right)$ and $3.05 \pm 0.19 \mathrm{~g} \mathrm{CMJ}^{-1}\left(R^{2}=85.9 \%\right)$ for rapeseed, wheat, peas and rye, respectively. The linear fit of these values versus the canopy height depicted in Fig. 6, was statistically significant at 95\% significance level.

\subsection{Inter-comparison between GPP and GPP MODIS retrievals}

$\varepsilon_{0 \text { MODIS }}$ was derived through inter-comparison between GPP and GPP AMODIS concurrent 8-d composites (see Fig. 1), defined here as the GPP 8-d MODIS retrievals divided by the $\varepsilon_{0}$ value originally prescribed for crops in the MODIS look-up Table, $0.604 \mathrm{~g} \mathrm{C} \mathrm{MJ}^{-1}$ (Running et al., 2000). Fig. 7 depicts the results of the linear fit 


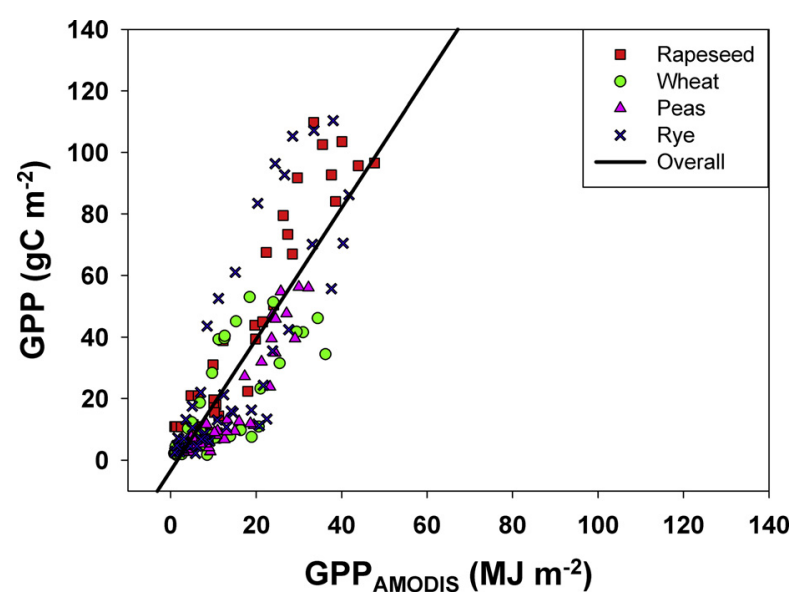

Fig. 7. Linear fit of observed GPP versus $\mathrm{GPP}_{\mathrm{AmoDIS}}$ 8-d composites for each crop type. Red, green, pink and blue symbols correspond to rapeseed, wheat, peas and rye, respectively, seeded in 2008, 2009, 2010 and 2011. The black line shows the overall linear fit for rapeseed, wheat, and rye. (For interpretation of the references to color in this figure legend, the reader is referred to the web version of the article.)

of GPP versus GPP AmODis. Coloured symbols, red, green, pink and blue, correspond to rapeseed, wheat, peas and rye, and the bold black line corresponds to the overall fit. Therefore, the slope of the linear fit accounts for the $\varepsilon_{0 \text { MODIS }}$ values based on validation results at our measuring site without any prior assumption of prescribed values. The results of the overall and individual crop-to-crop linear fits are shown in Table 2. Overall, the fit proved moderately satisfactory, $R^{2}=71.7 \%$, with the intercept being close to zero, $-3.21 \mathrm{~g} \mathrm{C} \mathrm{m}^{-2} 8$-d, and the slope, namely $\varepsilon_{0 \mathrm{MODIS}}$, $2.13 \pm 0.10 \mathrm{~g} \mathrm{CMJ}^{-1}$. Crop-to-crop results showed a strong correlation for rapeseed, $R^{2}=89.8 \%, \varepsilon_{0}=2.41 \pm 0.12 \mathrm{~g} \mathrm{CMJ}^{-1}$, and peas, $R^{2}=85.9 \%, \varepsilon_{0}=1.75 \pm 0.11 \mathrm{gC} \mathrm{MJ}^{-1}$ in contrast to rye, $R^{2}=66.5 \%$, $\varepsilon_{0}=2.30 \pm 0.25$ and wheat, $R^{2}=55.5 \%, \varepsilon_{0}=1.28 \pm 0.17 \mathrm{~g} \mathrm{CMJ}^{-1}$, for which the worst results were obtained. The comparison between the statistics shown in Table 2 reveals the better accuracy of the LUE model against the MODIS estimates overall. The first point worthy of note is the higher scatter of GPP $\left.\mathrm{MODIS}_{\text {MOMODIS }} \times \mathrm{GPP}_{\text {AMODIS }}\right)$ against GPP as compared with those obtained for GPP LUE modelled results (see Fig. 3c). This conclusion is also derived through the values of all the statistics, a lower $R^{2}$, and a higher MAE and RMSE. The second point worth noting is the GPP MODIS overestimation during summer, from July to September, a period of time during which GPP the LUE model and MODIS results have the same APAR, the differences found depend on the stress factors considered in each formulation, $f_{\mathrm{LUE}}\left(\mathrm{EF} T_{\mathrm{S}}\right)$ in this study and $f_{\mathrm{MODIS}}(D T)$. The main conclusion to be drawn from the preceding results is that the $f_{\mathrm{LUE}}$ considered here describes the GPP seasonal variation more realistically than $f_{\text {MODIs }}$ does. This is particularly true in summer when EF and SM drop dramatically to values as low as 0.1 and less than $5 \%$, respectively. It should also be noted that the best linear fits

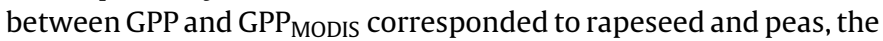
two well-watered crops, the worst fits being for wheat affected by drought.

\section{Discussion of the results}

\subsection{GPP}

The comparative analysis of the GPP patterns of each crop stresses the influence of the architecture, phenology and climatic conditions. The highest GPP values were obtained for crops with a denser and greater canopy height, rapeseed, $1.3 \mathrm{~m}$, and rye, $1.6 \mathrm{~m}$, which also exhibited the longest seasonal cycle, lasting around 143 and 135 days. The wider seasonal cycle of rapeseed could be attributed to the more temperate climatic conditions from mid May to mid June, $2008, T$ being $3.6^{\circ} \mathrm{C}$ lower than in 2011 , and to the higher accumulated rainfall, $80 \mathrm{~mm}$ against $50 \mathrm{~mm}$.

Rapeseed, peas and, in part, rye grew under well-watered conditions at the measuring site, accumulated rainfall during GS being 252,220 and $161 \mathrm{~mm}$, respectively. Conversely, wheat growing was affected by water stress, with rainfall in the GS dropping to $106 \mathrm{~mm}$. The influence of drought contributed greatly to an early GPP peak, which occurred in late April, and to reducing the maximum height of the canopy, which under well-watered conditions is usually $0.7-0.8 \mathrm{~m}$. Differences in the emergence and growing phenological stages in the case of peas, the crop seeded latest, in January, also explain the delay in the seasonal cycle, from April to late June.

Annual rapeseed and rye GPPs, 1680 and $1410 \mathrm{~g} \mathrm{C} \mathrm{m}^{-2}$, respectively were rather high compared to other results reported for winter crops including rapeseed (Béziat et al., 2009). In particular, the annual rapeseed GPP obtained in this study, a C3 plant, was comparable to $\mathrm{C} 4$ species, like corn, featured by higher light use efficiency and biomass production (Zhu et al., 2010). Reported annual GPP values for corn are $^{2} 789-1171 \mathrm{~g} \mathrm{C}^{-2}$ (Yan et al., 2009), and $1567 \mathrm{~g} \mathrm{C} \mathrm{m}^{-2}$ (Wang et al., 2012). The annual GPP of rye, although also high, is in the range of other results published, 744-2097 $\mathrm{g} \mathrm{C} \mathrm{m}^{-2}$ (Koizumi et al., 1990). ${ }^{2}$ The same occurred in the case of wheat and peas, 710 and $730 \mathrm{~g} \mathrm{C} \mathrm{m}^{-2}$, both values being in the range similar to those reported for crops (Zhao et al., 2005). In the case of peas, the annual GPP obtained in this study, $730 \mathrm{~g} \mathrm{C} \mathrm{m}^{-2}$ was lower than reported results of irrigated peas $\sim 1014-1180 \mathrm{~g} \mathrm{C} \mathrm{m}^{-2}$ (Giunta et al., 2009) ${ }^{2}$ and in the range of some similar legumes, e.g., chickpea, under and without water stress (Tesfaye et al., 2006) ${ }^{2} \sim 528-930 \mathrm{~g} \mathrm{C} \mathrm{m}^{-2}$. For wheat, annual $\mathrm{GPP}, 710 \mathrm{~g} \mathrm{C} \mathrm{m}^{-2}$ was similar to that reported by Yan et al. (2009), $602-729 \mathrm{~g} \mathrm{C} \mathrm{m}^{-2}$, and intermediate to extreme values, 900 and $500 \mathrm{~g} \mathrm{C} \mathrm{m}^{-2}$, recorded at another agricultural site located close to the measurement station (unpublished results) in 2003, a rainy year (602 $\mathrm{mm})$, and 2005 affected by severe drought $(276 \mathrm{~mm})$. The dramatic decline in 2005 proves the significant impact of droughts on GPP and therefore on crop inability to sequester $\mathrm{CO}_{2}$. This result emphasises the adverse consequences of climate change on crop production which might take place in future years due to the increase in temperature foreseen by the $\operatorname{IPCC}(2007,2013)$. Rapeseed, wheat, pea and rye accumulated GPP in GS was 1220, 550, 520 and $1130 \mathrm{~g} \mathrm{C} \mathrm{m}^{-2}$. Despite the large differences found between the different crops, the contribution of the GS to the annuals was rather conservative, and accounted for $72.4,77.2,71.2$ and $80.4 \%$ for the same crops.

The LUE model applied has properly fitted overall GPP $\left(R^{2}=86.1 \%\right)$ as well as crop-to-crop ( $R^{2}$ ranged from 90.8 to $\left.77.8 \%\right)$, showing a significant improvement compared to concurrent $\mathrm{GPP}_{\text {MODIS }}$ products $\left(R^{2}=71.7 \%\right)$. The main GPP MODIS $_{\text {inaccuracies }}$ have primarily been attributed to differences in the defined stress factor, $f_{\text {MODIS }}$ on $D$ and $T$ with respect to $f_{\text {LUE }}$ on EF and $T_{\mathrm{S}}$ used in this study. GPP exhibited a satisfactory correlation with $f_{\text {LUE }}$ in $\mathrm{GS}, R^{2}=59.7 \%$ proving its suitability to describe water availability in contrast with the weak correlation found when $f_{\text {MODIS }}$ is considered, $R^{2}=12.4 \%$. This result, together with the better linear fits of GPP versus GPP MODIs obtained for crops less affected by environmental stress, rapeseed and peas, supports the interpretation given.

\footnotetext{
2 NPP data reported by authors have been transformed to GPP using a ratio of 0.55 (see Eqs. (11) and (12)).
} 


\subsection{Maximum light use efficiency}

Despite the abundant literature existing on $\varepsilon$ values for different crop type, comparisons of our results with others reported are difficult given the different experimental methods used for NPP or GPP estimates and units used by authors. Thus, in some of the many field experiments based on NPP measurements, either total or above ground biomass production, results are expressed in $g$ DM $\mathrm{MJ}^{-1}$ of dry matter, DM, whereas in others, e.g., eddy correlation measurements, results are expressed in $\mathrm{gC} \mathrm{MJ}^{-1}$ absorbed by photosynthesis uptake. For unit conversion here, we use a similar approach to that reported by Lobell et al. (2002):

$\varepsilon_{\mathrm{NPP}}\left(\mathrm{g} \mathrm{C} \mathrm{MJ}^{-1}\right)=\varepsilon_{\text {biomass }}\left(\mathrm{g} \mathrm{DM} \mathrm{MJ} \mathrm{J}^{-1}\right) F S^{-1}$

where $F$ is the conversion unit of $\mathrm{g} D \mathrm{DM}$ to $\mathrm{g} C$ and $S$ the carbon production. In this study, we considered $F$ to be equal to $0.47 . S$ was considered 1 or 0.8 depending on the reported values, namely, total or above ground carbon, respectively. Whenever no information was found, we assumed $S=1$. Finally, conversion to $\varepsilon_{\mathrm{GPP}}$ was performed:

$\varepsilon_{\mathrm{GPP}}\left(\mathrm{g} \mathrm{C} \mathrm{MJ}^{-1}\right)=R \varepsilon_{\mathrm{NPP}}\left(\mathrm{g} \mathrm{C} \mathrm{MJ}^{-1}\right)$

where $R$ is the NPP:GPP ratio, considered here to be 0.55 , the average value of those reported for crops (Aubinet et al., 2009; Beer et al., 2010; King et al., 2011; Moureaux et al., 2008).

An additional remark concerns solar radiation. Here, we normalize all results to PAR $\mathrm{MJ}^{-1}$. Results expressed as a function of solar radiation (SR) were converted to PAR by dividing SR by 2 . Finally, it should also be highlighted that a number of $\varepsilon$ results reported based on biomass measurements were obtained under the climate conditions driving field experiments, meaning they may have been affected by water stress. In fact, the influence of an increase in $D$ on subsequent $\varepsilon$ decline is discussed by Kemanian et al. (2004). As a result, such comparisons with our results should be treated with caution. In contrast, results may be better compared when LUE models are applied to GPP or NPP results from EC fluxes, since they usually include stress factors in their formulation and, hence, report $\varepsilon_{0}$.

The $\varepsilon_{\text {OLUE }}$ value obtained in this study, $3.33 \mathrm{gC} \mathrm{MJ}^{-1}$, is in the range of those reported for the crops studied, ranging from 1.61 to $3.60 \mathrm{~g} \mathrm{CMJ}^{-1}$ (Akmal and Janssens, 2004; Lobell et al., 2002). Although various studies have shown that different crops have differing $\varepsilon_{0}$ values (Chen et al., 2011; Turner et al., 2006), the results published for a specific crop also present significant variability. For wheat, they range from 1.92 to $3.42 \mathrm{~g} \mathrm{CMJ}^{-1}$ (García et al., 1988; Lobell et al., 2002; Muurinen and Peltonen-Sainio, 2006; O'Connell et al., 2004). Reported values for peas range from 1.52 to $2.11 \mathrm{~g} \mathrm{CMJ}^{-1}$ (Giunta et al., 2009; Lecoeur and Ney, 2003; Worku and Demisie, 2012). For canola and rapeseed, the values are 2.16 and 2.05, $\mathrm{g} \mathrm{CMJ}^{-1}$, respectively (Justes et al., 2000; Soetedjo et al., 1998), and for rye they range from 2.04 to $3.60 \mathrm{~g} \mathrm{C} \mathrm{MJ}^{-1}$ (Akmal and Janssens, 2004). The significant differences reported might be attributed to many factors, such as irrigation, climate conditions, rotation schemes and agricultural management practices. Our results are in agreement with the variability observed for a specific crop and crop-to-crop, $\varepsilon_{\text {OLUE }}$ ranging from 2.74 to $3.95 \mathrm{~g} \mathrm{C} \mathrm{MJ}^{-1}$ for peas and rye, respectively, the larger values tending to be associated to crops with denser and taller canopies, rapeseed and rye. In dense canopies, more leaves are shaded and operate in the linear portion of the light response curve increasing the $\varepsilon$ of the canopy as a whole. Conversely, in sparse canopies most leaves experience a similar light regimen, resulting in a decline in $\varepsilon$. It is also usually assumed that erect canopies of tall species, rye being one clear example, absorb incident radiation very efficiently without starving the shaded component optimal levels of transmitted radiation (Yahuza, 2011).

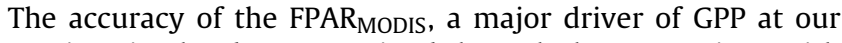
measuring site, has been examined through the comparison with the original retrievals and recomputed FPAR $_{\text {RMODIS }}$ derived from LAI ground measurements. The results have shown the underes-

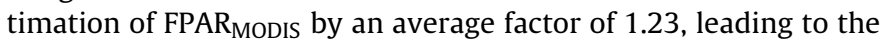
subsequent decline in the $\varepsilon_{0 \mathrm{~N}}$ values obtained by the LUE model, overall and crop-to crop. The recomputed crop-to-crop $\varepsilon_{0 N}$ results were correlated with the height of crops, thus indicating the dependence of canopy height and architecture, the greater the values, the denser and taller the canopies and conversely.

Another interesting result concerns the different magnitude

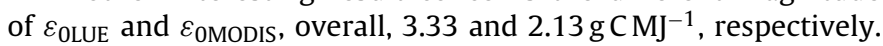
$\varepsilon_{\text {OLUE }}: \varepsilon_{\text {OMODIS }}$ ratio was 1.56 overall and varied, depending on crop type, the values being $1.21,2.23,1.57$ and 1.72 for rapeseed, wheat, peas and rye, respectively, the lower the ratios the better the watered conditions prevailing in GS (rapeseed and peas) and conversely, the greater the ratios the worse the watered conditions (wheat). Indeed, $\varepsilon_{0 \text { LUE }}: \varepsilon_{0 \text { MODIS }}$ was inversely proportional to the $f_{\text {LUE }}: f_{\text {MODIS }} 0.69$ on average (the ratio was computed using the overall individual 8-d composites data). This result highlights the important role in the $f$ formulation included in the LUE model on $\varepsilon_{0}$ results.

\section{Conclusions}

We present the most salient results of GPP seasonal evolution observed and modelled for a biofuel crop in the Spanish Plateau, consisting of annual rotation of non-irrigated rapeseed, wheat, peas and rye. The influence of crop architecture, phenology and climatic conditions dominated crop-to-crop seasonal evolution of

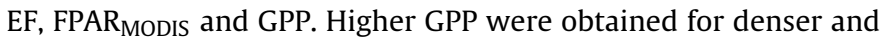
higher canopy height crops, rapeseed and rye. Both exhibited a marked EF seasonal variation driven by evapotranspiration, higher FPAR peaks and longer seasonal cycles. Rapeseed and rye also yielded high GPP annuals, almost comparable to C4 plants.

The LUE model applied to derive GPP provided satisfactory overall and crop-to-crop. The $\varepsilon_{0 \text { LUE }}$ varied depending on crop type, with higher values tending to be linked to higher density and canopy height. Although MODIS captured crop-to-crop FPAR MODIS seasonal $_{1}$ evolution quite well, it tended to underestimate derived ground based FPAR by a factor close to 1.2. Indeed, observed underestimation led to the opposite effects on $\varepsilon_{0 \mathrm{~N}}$ in a similar ratio. These new values were linearly related with canopy height, with the linear fit being statistically significant at 95\% significance level. However, this conclusion should be treated with caution given the limited data available, four years. Additional measurements with variable canopy heights are required to confirm whether or not this conclusion is maintained.

$\mathrm{GPP}_{\text {MODIS }}$ calibrated products provided satisfactory results for well-watered crops. The less accurate results under water stress, which were particularly noticeable for wheat and in summer, have been attributed to differences in the formulation of $f_{\text {MODIs }}$ versus $f_{\text {LUE }}$ considered in this study. In particular, $f_{\text {LUE }}$ on EF provided a better description of the environmental stress conditions than $f_{\text {MODIS }}$ on $D$ at our measuring site. Despite the less accurate GPP ${ }_{\text {MoDIS }}$ compared to the results obtained with the LUE model, inter-comparison results with GPP evidence the satisfactory potential of MODIS to routinely quantify GPP of crops. Improving current GPPMODIS retrievals could likely be achieved by updating the original lookup-table and including crop type discrimination.

\section{Acknowledgements}

This paper has been funded by the Spanish Ministry of Economy and Competitiveness, MICINN and ERDF funds. The authors wish 
to thank Carlos Blanco for his contribution to data processing and Jerónimo Alonso, owner of the Monte de Rocío farm, where measurements were conducted. We also wish to thank the NASA for providing us with free access to the MODIS products.

\section{References}

Albergel, C., Calvet, J.C., Gibelin, A.L., Lafont, S., Roujean, J.L., Berne, C., Traullé, O., Fritz, N., 2010. Observed and modelled ecosystem respiration and gross primary production of a grassland in Southwestern France. Biogeosciences 7, 1657-1668.

Akmal, M., Janssens, M.J.J., 2004. Productivity and light use efficiency of perennial ryegrass with contrasting water and nitrogen supplies. Field Crops Res. 88, 143-155.

Atwell, B.A., Kriedemann, P.E., Turnbull, C., 1999. Plants in Action: Adaptation in Nature and Performance in Cultivation. Macmillan Education Australia, Melbourne, Australia, pp. 664.

Aubinet, M., Moureaux, C., Bodson, B., Dufranne, D., Heinesch, B., Suleau, M., Vancutsem, F., Vilret, A., 2009. Carbon sequestration by a crop over a 4-year sugar beet/winter wheat/seed potato/winter wheat rotation cycle. Agric. For. Meteorol. 149, 407-418.

Baldocchi, D., Falge, E., Gu, L., Olson, R., Hollinger, D., Running, S., Anthoni, P., Bermhofer, C., Davis, K., Evans, R., Fuentes, J., Goldenstein, A., Katul, G., Law, B., Lee, X., Malhi, Y., Meyers, T., Munger, W., Oecheel, W., Paw, U.K.T., Pilegaard, K., Schmid, H.P., Valentini, R., Verma, S., Vesala, T., Wilson, K., Wosfy, S., 2001. FLUXNET: a new tool to study the temporal and spatial variability of ecosystem-scale carbon dioxide, water vapor and energy flux densities. Bull. Am. Meteorol. Soc. 82, 2415-2434.

Baldocchi, D., 2008. Turner review no. 15. 'Breathing' of the terrestrial biosphere: lessons learned from a global network of carbon dioxide flux measurement systems. Aust. J. Bot. 56, 1-26.

Beer, C., Reichstein, M., Tomelleri, E., Ciais, P., Jung, M., Carvalhais, N., Rödenbeck, C., Arain, M.A., Baldocchi, D., Bonan, G.B., Bondeau, A., Cescatti, A., Lasslop, G., Lindroth, A., Lomas, M., Luyssaert, S., Margolis, H., Oleson, K.W., Roupsard, O., Veenendaal, E., Viovy, N., Williams, C., Woodward, F.I., Papale, D., 2010. Terrestrial gross carbon dioxide uptake: global distribution and covariation with climate. Science 329, 834-838, http://dx.doi.org/10.1126/science. 1184984.

Béziat, P., Ceschia, E., Dedieu, G., 2009. Carbon balance of a three crop succession over two cropland sites in South West France. Agric. For. Meteorol. 149 $1628-1645$

Chen, T., van der Werf, G.R., Dolman, A.J., Groenendijk, M., 2011. Evaluation of cropland maximum light use efficiency using eddy flux measurements in North America and Europe. Geophys. Res. Lett. 38, L14707, http://dx.doi.org/ 10.1029/2011GL047533.

Elhag, M., Psilovikos, A., Manakos, I., Perakis, K., 2011. Application of the Sebs water balance model in estimating daily evapotranspiration and evaporative fraction from remote sensing data over the Nile Delta. Water Resour. Manage. $25,2731-2742$.

Fensholt, R., Sandholt, I., Rasmussen, M.S., Stisen, S., Diouf, A., 2006. Evaluation of satellite based primary production modelling in the semi-arid Sahel. Remote Sens. Environ. 105, 173-188.

García, R., Kanemasu, E.T., Blad, B.L., Hatfield, J.L., Major, D.J., Reginato, R.J., Hubbard, K.G., 1988. Interception and use efficiency of light in winter wheat under different nitrogen regimes. Agric. For. Meteorol. 44, 175-186.

Gebremichael, M., Barros, A.P., 2006. Evaluation of MODIS. Gross primary productivity (GPP) in tropical monsoon regions. Remote Sens. Environ. 100, $150-166$.

Gilmanov, T.G., Wylie, B.K., Tieszen, L.L., Meyers, T.P., Baron, V.S., Bernacchi, C.J., Billesbach, D.P., Burba, G.G., Fischer, M.L., Glenn, A.J., Hanan, N.P., Hatfield, J.L., Heuer, M.W., Hollinger, S.E., Howard, D.M., Matamala, R., Prueger, J.H., Tenuta, M., Young, D.G., 2013. $\mathrm{CO}_{2}$ uptake and ecophysiological parameters of the grain crops of midcontinent North America: estimates from flux tower measurements. Agric. Ecosyst. Environ. 164, 162-175.

Giunta, F., Pruneddu, G., Motzo, R., 2009. Radiation interception and biomass and nitrogen accumulation in different cereal and grain legume species. Field Crops Res. 110, 76-84.

Hashimoto, H., Wang, W., Milesi, C., White, M.A., Ganguly, S., Gamo, M., Hirata, R., Myneni, R.B., Nemani, R.R., 2012. Exploring simple algorithms for estimating gross primary production in forested areas from satellite data. Remote Sens. 4 , 303-326.

IPCC, 2007. Climate Change 2007: The Sciences Basis. Intergovernmental Panel of Climate Change. Cambridge University Press, UK, pp. 18.

IPCC, 2013. Climate Change 2013: The Physical Sciences Basis. Contribution of Working Group I to the Fifth Assessment Report of the Intergovernmental Panel on Climate Change. Cambridge University Press, UK, pp. 1535.

Jaksic, V., Kiely, G., Albertson, J., Oren, R., Katul, G., Leahy, P., Byrne, K.A., 2006. Net ecosystem exchange of grassland in contrasting wet and dry years. Agric. For Meteorol. 139, 323-334.

Justes, E., Denoroy, P., Gabrielle, B., Gosse, G., 2000. Effect of crop nitrogen status and temperature on the radiation use efficiency of winter oilseed rape. Eur. J. Agron. 13, 165-177

Kemanian, A.R., Stöckle, C.O., Huggins, D.R., 2004. Variability of barley radiation-use efficiency. Crop Sci. 44, 1662-1672.
King, D.A., Turner, D.P., Ritts, W.D., 2011. Parameterization of a diagnostic carbon cycle model for continental scale application. Remote Sens. Environ. 115, 1653-1664.

Koizumi, H., Usami, Y., Satoh, M., 1990. Annual net primary production and efficiency of solar-energy utilization in 3 double-cropping agroecosystems in Japan. Agric. Ecosyst. Environ. 32, 241-255.

Lafont, S., Kergoat, L., Dedieu, G., Chevillard, A., Karstens, U., Kolle, O., 2002. Spatial and temporal variability of land $\mathrm{CO}_{2}$ fluxes estimated with remote sensing and analysis data over western Eurasia. Tellus 54B, 820-833.

Lecoeur, J., Ney, B., 2003. Change with time in potential radiation-use efficiency in field pea. Eur. J. Agron. 19, 91-105.

Leuning, R., Cleugh, H.A., Zegelin, S.J., Hughes, D., 2005. Carbon and water fluxes over a temperate eucalyptus forest and a tropical wet/dry savannah in Australia: measurements and comparison with MODIS remote sensing estimates. Agric. For. Meteorol. 129, 151-173.

Li, Z., Yu, G., Xiao, X., Li, Y., Zhao, X., Ren, C., Zhang, L., Fu, Y., 2007. Modeling gross primary production of alpine ecosystems in the Tibetan Plateau using MODIS images and climate data. Remote Sens. Environ. 107, 510-519.

Lobell, D.B., Hicke, J.A., Asner, G.P., Field, C.B., Tucker, C.J., Los, S.O., 2002. Satellite estimates of productivity and light use efficiency in United States agriculture, 1982-98. Global Change Biol. 8, 722-735.

Lu, J., Li, Z., Tang, R., Tang, B., Wu, H., Yang, F., Labed, J., Zhou, G., 2013. Evaluating the SEBS-estimated evaporative fraction from MODIS data for a complex underlying surface. Hydrol. Process. 27, 3139-3149.

MAGRAMA, 2013. Anuario de Estadística 2012. Gobierno de España. Ministerio de Agricultura, Alimentación y Medio Ambiente[[nl]]Spanish Ministry of Agriculture, Food, and Environment, Madrid, Spain.

Mauder, M., Foken, T., 2004. Documentation and Instruction Manual of the Eddy Covariance Software Package TK2. Arbeitsergebnisse, Universität Bayreuth, Abt. Mikrometeorologie, Print, ISSN 1614-8916.

Monteith, J.L., 1977. Climate and efficiency of crop production in Great Britain. Philos. Trans. R. Soc. Lond. B 281, 277-294.

Moureaux, C., Debacq, A., Hoyaux, J., Suleau, M., Tourneur, D., Vancutsem, F., Bodson, B., Aubinet, M., 2008. Carbon balance assessment of a Belgian winter wheat crop (Triticum aestivum L.). Global Change Biol. 14, 1353-1366.

Muurinen, S., Peltonen-Sainio, P., 2006. Radiation-use efficiency of modern and old spring cereal cultivars and its response to nitrogen in northern growing conditions. Field Crops Res. 96, 363-373.

O'Connell, M.G., O'Leary, G.J., Whitfield, D.M., Connor, D.J., 2004. Interception of photosynthetically active radiation and radiation-use efficiency of wheat, field pea and mustard in a semi-arid environment. Field Crops Res. 85, $111-124$.

Papale, D., Reichstein, M., Aubinet, M., Canfora, E., Bernhofer, C., Kutsch, W., Longdoz, B., Rambal, S., Valentini, R., Vesala, T., Yakir, D., 2006. Towards a standardized processing of net ecosystem exchange measured with eddy covariance technique: algorithms and uncertainty estimation. Biogeosciences 3, 571-583.

Paredes, V., (PhD thesis) 2013. Medida y parametrización de los flujos de $\mathrm{CO}_{2}$ en un uso de suelo agrícola de la meseta utilizando datos en superficie y teledetección. University of Valladolid, Spain, pp. 259.

Pardo, N., Sánchez, M.L., Timmermans, J., Su, Z., Pérez, I.A., García, M.A., 2014. SEBS validation in a Spanish rotating crop. Agric. For. Meteorol. 195-196, $132-142$.

Pardo, N., Sánchez, M.L., Pérez, I.A., García, M.A., 2015. Energy balance and partitioning over a rotating rapeseed crop. Agric. Water Manage. 161, 31-41.

Patel, N.R., Dadhwal, V.K., Saha, S.K., Garg, A., Sharma, N., 2010. Evaluation of MODIS data potential to infer water stress for wheat NPP estimation. Trop. Ecol. 51, 93-105.

Pei, F., Li, X., Liu, X., Lao, C., 2013. Assessing the impacts of droughts on net primary productivity in China. J. Environ. Manage. 114, 362-371.

Prince, S.D., Goward, S.N., 1995. Global primary production: a remote sensing approach. J. Biogeogr. 22, 815-835.

Reijnders, L., Huijbregts, M.A.J., 2008. Biogenic greenhouse gas emissions linked to the life cycles of biodiesel derived from European rapeseed and Brazilian soybeans. J. Clean. Prod. 16, 1943-1948.

Reichstein, M., Falge, E., Baldocchi, D., Papale, D., Aubinet, M., Berbigier, P., Bernhofer, C., Buchmann, N., Gilmanov, T., Granier, A., Grünwald, T., Havránková, K., Ilvesniemi, H., Janous, D., Knohl, A., Laurila, T., Lohila, A., Loustau, D., Matteucci, G., Meyers, T., Miglietta, F., Ourcival, J.M., Pumpanen, J., Rambal, S., Rotenberg, E., Sanz, M., Tenhunen, J., Seufert, G., Vaccari, F., Vesala, T., Yakir, D., Valentini, R., 2005. On the separation of net ecosystem exchange into assimilation and ecosystem respiration: review and improved algorithm. Global Change Biol. 11, 1424-1439.

Reichstein, M., Papale, D., Valentini, R., Aubinet, M., Bernhofer, C., Knohl, A., Laurila, T., Lindroth, A., Moors, E., Pilegaard, K., Seufert, G., 2007. Determinants of terrestrial ecosystem carbon balance inferred from European eddy covariance flux sites. Geophys. Res. Lett. 34, L01402, http://dx.doi.org/10.1029/ 2006GL027880.

Running, S.W., Baldocchi, D.D., Turner, D.P., Gower, S.T., Bakwin, P.S., Hibbard, K.A., 1999. A global terrestrial monitoring network integrating tower fluxes, flask sampling, ecosystem modelling and EOS satellite data. Remote Sens. Environ. 70, 108-127.

Running, S.R., Thornton, P.E., Nemani, R., Glassy, J.M., 2000. Global terrestrial gross and net primary productivity from the earth observing system. In: Sala, O.E. Jackson, R.B., Mooney, H.A., Howarth, R.W. (Eds.), Methods in Ecosystem Science. Springer, New York, pp. 44-57. 
Sánchez, M.L., Ozores, M., Colle, R., López, M.J., de Torre, B., García, M.A., Pérez, I., 2002. $\mathrm{CO}_{2}$ fluxes in cereal land use of the Spanish Plateau: influence of conventional and reduced tillage practices. Chemosphere 47 , $837-844$

Schulze, E.D., Luyssaert, S., Ciais, P., Freibauer, A., Janssens, I.A., Soussana, J.F. Smith, P., Grace, J., Levin, I., Thiruchittampalam, B., Heimann, M., Dolman, A.J., Valentini, R., Bousquet, P., Peylin, P., Peters, W., Rödenbeck, C., Etiope, G., Vuichard, N., Wattenbach, M., Nabuurs, G.J., Poussi, Z., Nieschulze, J., Gash, J.H. The CarboEurope Team, 2009. Importance of methane and nitrous oxide for Europe's terrestrial greenhouse-gas balance. Nat. Geosci. 2, 842-850, http://dx. doi.org/10.1038/ngeo686.

Sims, D.A., Rahman, A.F., Cordova, V.D., Baldocchi, D.D., Flanagan, L.B., Allen, H, Goldstein, A.H., Hollinger, D.Y., Misson, L., Monson, R.K., Schmid, H.P., Wofsy, S.C., Xu, L., 2005. Midday values of gross $\mathrm{CO}_{2}$ flux and light use efficiency during satellite overpasses can be used to directly estimate eight-day mean flux. Agric. For. Meteorol. 131, 1-12.

Smith, P., 2004. Carbon sequestration in croplands: the potential in Europe and the global context. Eur. J. Agron. 20, 229-236.

Smith, P., Martino, D., Cai, Z., Gwary, D., Janzen, H., Kumar, P., McCarl, B., Ogle, S. O’Mara, F., Rice, C., Scholes, B., Sirotenko, O., Howden, M., McAllister, T., Pan, G., Romanenkov, V., Schneider, U., Towprayoon, S., Wattenbach, M., Smith, J. 2008. Greenhouse gas mitigation in agriculture. Philos. Trans. R. Soc. Lond. Ser. B 363, 789-813, http://dx.doi.org/10.1098/rstb.2007.2184.

Soetedjo, P., Martin, L.D., Janes, J.V., 1998. Canopy architecture, light utilization and productivity of intercrops of field pea and canola. In: Michalk, D.L., Pratley, J.E. (Eds.), Agronomy, Growing a Greener Future? Proceedings of the 9th Australian Agronomy Conference. 20-23 July 1998. Charles Sturt University, Wagga Wagga, NSW.

Tao, B., Tian, H., Chen, G., Ren, W., Lu, C., Alley, K.D., Xu, X., Liu, M., Pan, S., Virji, H., 2011. Changes in carbon fluxes and pools induced by cropland expansion in South and Southeast Asia in the 20th century. Biogeosci. Discuss. 8, 11979-12012.

Tesfaye, K., Walker, S., Tsubo, M., 2006. Radiation interception and radiation use efficiency of three grain legumes under water deficit conditions in a semi-arid environment. Eur. J. Agron. 25, 60-70.

Turner, D.P., Ritts, W.D., Cohen, W.B., Gower, S.T., Zhao, M., Running, S.W., Wofsy, S.C., Urbanski, S., Dunn, A.L., Munger, J.W., 2003. Scaling gross primary production (GPP) over boreal and deciduous forest landscapes in support of MODIS GPP product validation. Remote Sens. Environ. 88, 256-270.

Turner, D.P., Ritts, W.D., Cohen, W.B., Maeirsperger, T.K., Gower, S.T., Kirschbaum, A.A., Running, S.W., Zhao, M.S., Wofsy, S.C., Dunn, A.L., Law, B.E., Campbell, J.L., Oechel, W.C., Kwon, H.J., Meyers, T.P., Small, E.E., Kurc, S.A., Gamon, J.A., 2005. Site-level evaluation of satellite-based global terrestrial gross primary production and net primary production. Monit. Global Change Biol. 11, 666-684.

Turner, D.P., Ritts, W.D., Cohen, W.B., Gower, S.T., Running, S.W., Zhao, M., Costa, M.H., Kirschbaum, A.A., Ham, J.M., Saleska, S.R., Ahl, D.E., 2006. Evaluation of MODIS NPP and GPP products across multiple biomes. Remote Sens. Environ. $102,282-292$.
Venturini, V., Islam, S., Rodríguez, L., 2008. Estimation of evaporative fraction and evapotranspiration from MODIS products using a complementary based model. Remote Sens. Environ. 112, 132-141.

Veroustraete, F., Sabbe, H., Eerens, H., 2002. Estimation of carbon mass fluxes over Europe using the C-Fix model and Euroflux data. Remote Sens. Environ. 83, 376-399.

Wang, K., Li, Z., Cribb, M., 2006. Estimation of evaporative fraction from a combination of day and night land surface temperatures and NDVI: a new method to determine the Priestley-Taylor parameter. Remote Sens. Environ. 102, 293-305.

Wang, Z., Xiao, X., Yan, X., 2010. Modeling gross primary production of maize cropland and degraded grassland in northeastern China. Agric. For. Meteorol. $150,1160-1167$.

Wang, X., Ma, M., Huang, G., Veroustraete, F., Zhang, Z., Song, Yi, Tan, J., 2012. Vegetation primary production estimation at maize and alpine meadow over the Heihe River Basin, China. Int. J. Appl. Earth Obs. Geoinf. 17, 94-101.

West, T.O., Brandt, C.C., Baskaran, L.M., Hellwinckel, C.M., Mueller, R., Bernacchi, C.J., Bandaru, V., Yang, B., Wilson, B.S., Marland, G., Nelson, R.G., de la Torre Ugarte, D.G., Post, W.M., 2010. Cropland carbon fluxes in the United States: increasing geospatial resolution of inventory-based carbon accounting. Ecol. Appl. 20, 1074-1086.

Wolfe R., Nishihama, M., Kuyper, R, 2012. http://mcst.gsfc.nasa.gov/sites/mcst.gsfc/ files/meetings_files/STM2012_Cal_Wolfe.pdf.

Wolfe, R.E., Nishihama, M., Fleig, A.J., Kuyper, J.A., Roy, D.P., Storey, J.C., Patt, F.S., 2002. Achieving sub-pixel geolocation accuracy in support of MODIS land science. Remote Sens. Environ. 83, 31-49.

Worku, W., Demisie, W., 2012. Growth, light interception and radiation use efficiency response of Pigeon pea (Cajanus cajan) to planting density in Southern Ethiopia. J. Agron. 11, 85-93.

Xiao, X., Zhang, Q., Saleska, S., Hutyra, L., De Camargo, P., Wofsy, S., Frolking, S., Boles, S., Keller, M., Moore III, B., 2005. Satellite-based modeling of gross primary production in a seasonally moist tropical evergreen forest. Remote Sens. Environ. 94, 105-122.

Yahuza, I., 2011. Review of radiation interception and radiation use efficiency in intercropping in relation to the analysis of wheat/faba bean intercropping system. J. Biodivers. Environ. Sci. 1, 1-15.

Yan, H., Fu, Y., Xiao, X., Huang, H.Q., He, H., Ediger, L., 2009. Modeling gross primary productivity for winter wheat-maize double cropping system using MODIS time series and $\mathrm{CO}_{2}$ eddy flux tower data. Agric. Ecosys. Environ. 129, 391-400.

Yuan, W., Liu, S., Zhou, G., Zhou, G., Tieszen, L.L., Baldocchi, D., Bernhofer, C., Gholz, H., Goldstein, A.H., Goulden, M.L., Hollinger, D.Y., Hu, Y., Law, B.E., Stoy, P.C., Vesala, T., Wofsy, S.C., other AmeriFlux collaborators, 2007. Deriving a light use efficiency model from eddy covariance flux data for predicting daily gros primary production across biomes. Agric. For. Meteorol. 143, 189-207.

Zhao, M., Heinsch, F.A., Nemani, R.R., Running, S.W., 2005. Improvements of the MODIS terrestrial gross and net primary production global data set. Remote Sens. Environ. 95, 164-176.

Zhu, X.-G., Long, S.P., Ort, D.R., 2010. Improving photosynthetic efficiency for greater yield. Annu. Rev. Plant Biol. 61, 235-261. 